\title{
Endocrine Secretory Process
}

National Cancer Institute

\section{Source}

National Cancer Institute. Endocrine Secretory Process. NCI Thesaurus. Code C41493.

Endocrine Secretory Induction involves stimulation of hormone release into the bloodstream from endocrine glands. Alteration of positive or negative feedback mechanisms can induce hormone release. 